\title{
2-(2-ヒドロキシ-5-メトキシフェニルアゾ)-4-メチル チアゾールによる重鉛の定量*
}

\author{
柳 原 正, 俣野 宣久, 川瀬 晃**
}

\begin{abstract}
2-(2-ヒドロキシ-5-メトキシフエニルアゾ)-4-メチルアゾールは亜鉛イオンと青色のキレート化合物 を生成し，乙れは 2 種あるものと考えられる。

$\mathrm{pH}$ の低いときまたは亜鉛濃度の高いときには,水溶性の $1: 1$ の組成を有するキレート化合物を生成 し,その水溶液は $398,594 \mathrm{~m} \mu$ に二つの極大吸収を有し,てのキレート生成定数 $\log K$ は約 5.9 である.

$\mathrm{pH}$ の高いときには，水に難溶性のキレート化合物を生成し沈澱する．とれはイソアミルアルコール などの有機溶媒に可溶で,イソアミルアルコール溶液は 398, $612 \mathrm{~m} \mu$ につの極大吸収を有する．ての キレート化合物は亜鉛 1 原子に 2 分子の試薬が結合しているものである．イソアミルアルコールに易溶 なので水層より抽出ができ，微量の亜鉛の吸光光度定量が括てなえる．その感度 ${ }^{1}$ は $0.0019 \mathrm{r} \mathrm{Zn} / \mathrm{cm}^{2}$ である．また EDTAによる錯滴定の際の金属指示薬として使用できる。
\end{abstract}

\section{1 試薬および装置}

亜鉛標準溶液 : $5 \times 10^{-2} M$, 標準业鉛 $3.269 \mathrm{~g}$ を硝酸 $(1+3) 20 \mathrm{~m} l$ に溶解し, 水で $1 . l$ に稀める.

試薬溶液 : $5 \times 10^{-4} M$, 合成品 $124.6 \mathrm{mg}$ を和光純薬 製特級メタノールに溶解し, $1 l$ とする.

緩衝溶液 : 和光純薬製特級唧砂 $19 \mathrm{~g}$ を溶解, 塩酸で 所定の $\mathrm{pH}$ に調節し, $1 l$ に稀める.

EDTA 溶液 : $10^{-2} M$, 第一化学薬品製特級 EDTA $3.723 \mathrm{~g}$ を水に溶解し， $1 l$ とする. 力価は標準亜鉛を用 いて決定する.

イソアミルアルコールその他の薬品はすべて和光純薬 製特級品を使用した.

吸収スペクトルの測定にはベックマン DK 2 型自記分 光光電光度計に $10 \mathrm{~mm}$ の石英製セルを用い, $\mathrm{pH}$ の測

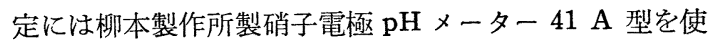
用した。

\section{2 亜鉛キレート化合物}

\section{$2 \cdot 1$ 吸収スペクトル}

亜鉛は $\mathrm{pH}$ の低いときは $1: 1$, 高いときは $1: 2$ の キレート化合物を生成する. $1: 1$ のキレート化合物は 水溶性で水溶液は $398,594 \mathrm{~m} \mu$ に二つの極大吸収を有 し, 1:2のキレート化合物は水に難溶でイソアミルアル

\footnotetext{
*分析試薬としての 2-(2-ヒドロキシー5-メトキシフ
} エニルアゾ)-4-メチルチアゾールの研究（第 3 報）

** 科学技術庁金属材料技術研究所 : 東京都目黒区中目 黒
コールによく溶解し水層より抽出され, $398,612 \mathrm{~m} \mu$ に 二つの極大吸収を有する。

Fig. 1 にこの 2 種のキレート化合物と試薬の吸収ス ペクトルを示した.

1:1 のキレート化合物は $5 \times 10^{-4} M$ 試薬 $1 \mathrm{ml}$ を $\mathrm{pH} 5.12$ の酢酸ナトリウム-塩酸緩衝溶液に加え, $5 \times$ $10^{-2} M$ の亜鉛溶液 $10 \mathrm{~m} l$ を加え, 水で $25 \mathrm{~m} l$ とし $(\mu=$ $0.1)$ 吸収スペクトルを水を対照液として測定した。

$1: 2$ のキレート化合物は試薬 $1 \mathrm{ml}$ を髣衝溶液 $\mathrm{pH}$ $9.0,20 \mathrm{ml}$ に加え $5 \times 10^{-3} M$ 亜鉛溶液 $1 \mathrm{ml}$ を加えて $10 \mathrm{ml}$ のイソア乏ルアルコールで抽出, 綿フィルターで 水分を除いてのち, イソアミルアルコールを対照液とし て吸収スペクトルを測定した。なお，試薬の吸収スペク トルは EDTAを $1 \mathrm{~m} l$ 加え金属を鿵蔽し，同様に操作

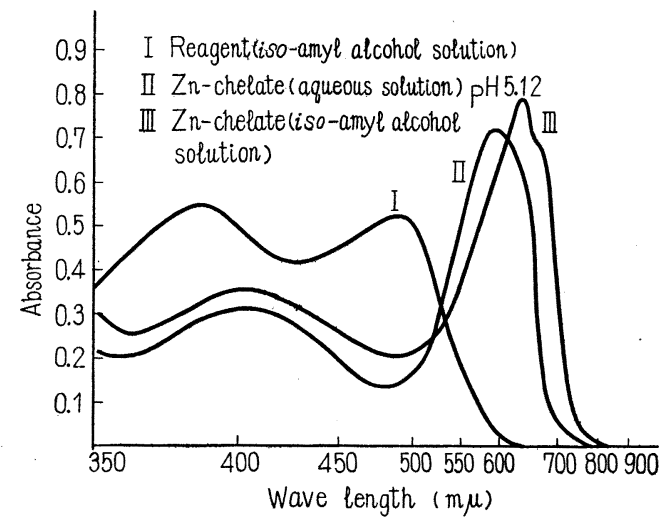

Fig. 1 Absorption spectra of reagent and zinc-chelates 
して吸収スペクトルを測定した.

このキレート化合物は安定でイソアミルアルコール溶 液は少なくとも 1 日放置しても吸光度, 吸収スペクトル に変化はなかった。

\section{$2 \cdot 2$ pH の影響}

亜鉛の吸光光度定量を目的として $1: 2$ のキレート化 合物について種々の $\mathrm{pH}$ の亜鉛を含む溶液中よりイソア ミルアルコールに抽出されるキレート化合物の量を吸光 度によって求め, 光度定量に最適の $\mathrm{pH}$ を求めた.

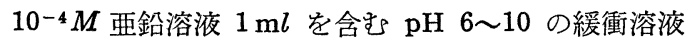
$20 \mathrm{~m} l$ に試薬 $2 \mathrm{~m} l$ を加え, $10 \mathrm{~m} l$ のイソア そルアルコー ルで抽出をおこない， $612 \mathrm{~m} \mu$ における吸光度を測定し た. 同様にして亚鉛を含まない溶液について空試験値を 求めてそれぞれ Fig. 2 に示した. これによると $\mathrm{pH}$ 8.4 9.2 では一定の吸光度を示している. $\mathrm{pH} 9.5$ 以 上ではイオン化している試薬が水層に残る傾向を生じて くるので，これ以下の $\mathrm{pH}$ で抽出をおこなう必要があ り，本実験では pH 9.0 をとることにした.

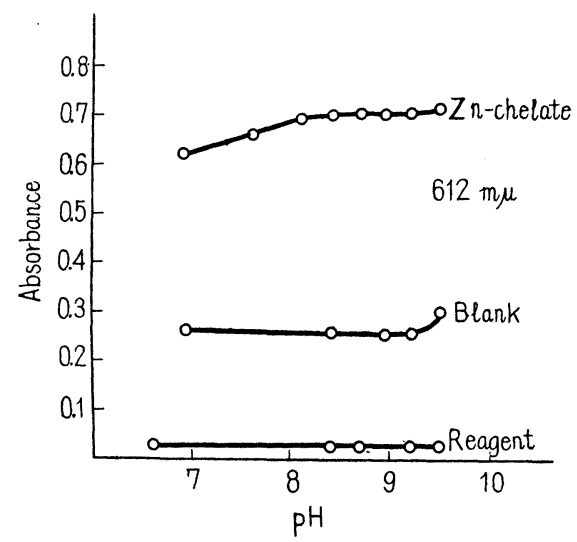

Fig. 2 Effect of $\mathrm{pH}$ on extraction of reagent and $z$ inc chelate with $i$ so-amyl alcohol

\section{$2 \cdot 3$ キレート化合物の組成}

2.3.1 連続変化法 $2 \times 10^{-4} M$ の試薬および亜鉛 溶液を合計 $4.40 \mathrm{ml}$ に $\mathrm{pH} 9.0$ の緩衝溶液 $10 \mathrm{ml}$, 水 $10 \mathrm{~m} l$ に加えて, イソアミルアルコール $10 \mathrm{~m} l$ で抽出を おこない, $612 \mathrm{~m} \mu$ における吸光度を測定した. これを Fig. 3 に示した.これは $1: 2.14$ の結合比を示してお り，1:2 のキレート化合物の生成を示している.

2.3.2 傾斜比法 固定成分の量を $5 \times 10^{-4} M 2 \mathrm{ml}$ とし，変化成分 $10^{-4} M$ を $0 \sim 3 \mathrm{ml}$ まで変化させて， pH 9.0 の緩衝溶液 $10 \mathrm{ml}$, 水 $10 \mathrm{~m} l$ に加えて, $10 \mathrm{ml}$

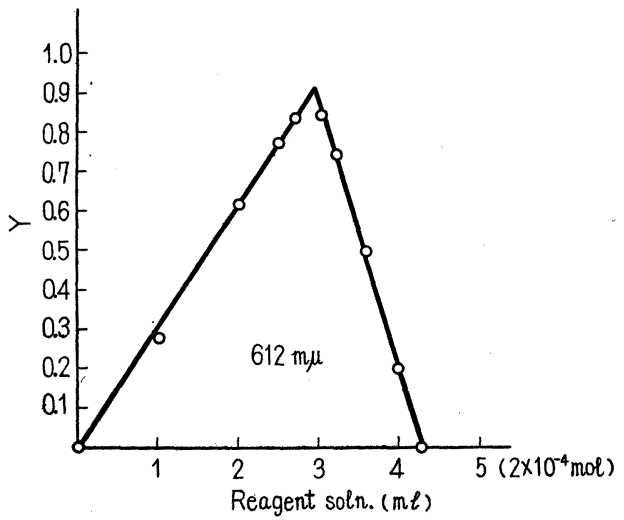

Fig. 3 Continuous variation method applied to zinc-chelate

のイソアミルアルコールで抽出し, $612 \mathrm{~m} \mu$ における吸 光度を測定した. この傾斜比は $1: 2.44$ で,これも $1: 2$ のキレート化合物の生成を示している（Fig.4).

2.3.3 等吸収点 試薬 $1 \mathrm{ml}$ を $\mathrm{pH} 9.0$ の緩衝溶 液 $20 \mathrm{~m} l$ 中に加え, $2 \times 10^{-5} M$ 亜鉛溶液を $0 \sim 4 \mathrm{~m} l$, 括 よび $10^{-2} M$ 亜鉛溶液を $1 \mathrm{~m} l$ 加えて, 試薬のすべてを キレート化合物とし，イソアミルアルコールで抽出, 450〜900 m $\mu$ の吸収スペクトルを測定した（Fig. 5). なお，亜鉛を加えないときは，EDTA を加えて不純物 として含まれている金属イオンを隠蔽した。これらの曲 線はすべて $533 \mathrm{~m} \mu$ に集まり，この条件下ではただ一種 のキレート化合物を生成していることを示している.

\section{5 キレート生成定数の測定}

$\mathrm{pH}$ の低いときまたは亜鉛濃度の高い場合では, pH

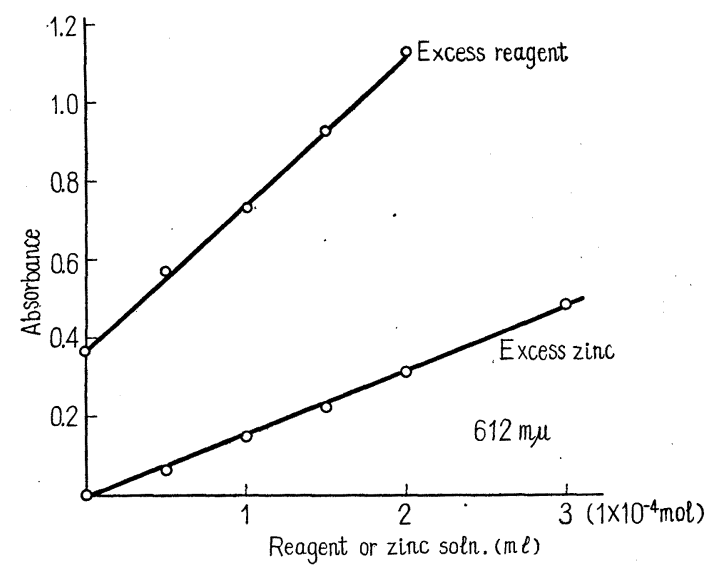

Fig. 4 Slope ratio method applied to zinc-chelate 


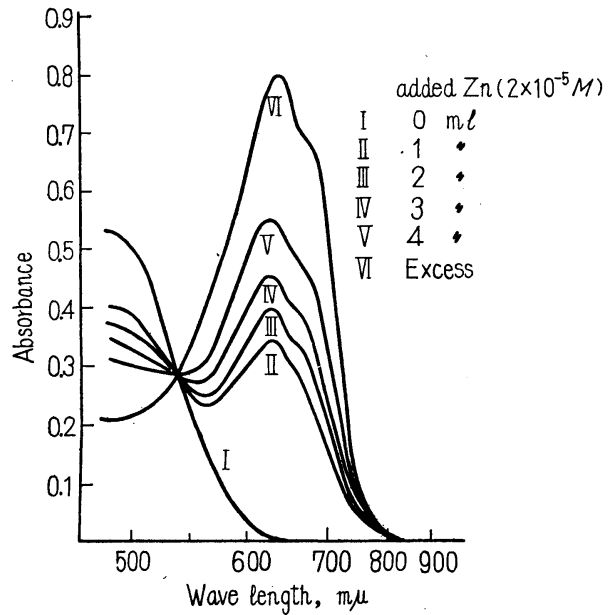

Fig. 5 Absorption spectra showing isosbestic point

の高い場合でのようにキレート化合物は沈澱することな く，水溶液となっている. この現象は銅キレート化合物 の場合にも見られ 1:1 のキレート化合物の生成を連続 変化法，傾斜比法などにより確認している．亜鉛の場合 にも同様なことが考えられ，1:1のキレート化合物の存 在が $\mathrm{pH}$ と吸光度との関係により推定される.

G. P. Hilderbrand, C. N. Reilley²)の方法により, 1: 1 のキレート化合物が生成しているとして, キレー 卜生成定数の近似值を求めた.

pH 1〜6 では次の反応が主であると考えられる.

$$
\begin{array}{r}
\mathrm{Zn}^{2+}+\mathrm{HM} \rightleftarrows \mathrm{ZnM}^{+}+\mathrm{H}^{+} \\
\mathrm{HM}: \text { 試薬 }
\end{array}
$$

$$
\begin{gathered}
\therefore \log K^{\prime}=\log \frac{\left[\mathrm{ZnM}^{+}\right]}{[\mathrm{HM}]}+\log \left[\mathrm{H}^{+}\right]-\log \left[\mathrm{Zn}^{2+}\right] \cdots(2) \\
K^{\prime}: \text { 平衡定数 }
\end{gathered}
$$

$$
\log K=\log K^{\prime}+p K_{2}
$$

$\log K:$ キレート生成定数 $p K_{2}:$ 第 2 段の酸解離指数

$\log \left\{\left[\mathrm{ZnM}^{+}\right] /[\mathrm{HM}]\right\}$ が 0 となるような $\log \left[\mathrm{H}^{+}\right]$を 求めれば $\log \left[Z_{\mathrm{n}^{2+}}\right.$ より $\log K^{\prime}$ は求められ, 従って (3) 式によりキレート生成定数は求められる.

亜鉛濃度 $2 \times 10^{-2} M$, 試薬濃度 $4 \times 10^{-5} M$ の溶液を 酢酸ナトリウムー塩酸で $\mathrm{pH}$ を変化させる $(\mu=0.1)$. 吸光度を $594 \mathrm{~m} \mu$ で測定し，この結果を Fig. 6 に示 した。

Fig. 6 より $\mathrm{pH}$ と $\log \left\{\left[\mathrm{ZnM}^{+}\right] /[\mathrm{HM}]\right\}$ の関係を 求め, $\mathrm{pH}$ 軸との交点 3.78 を得た（Fig. 7).

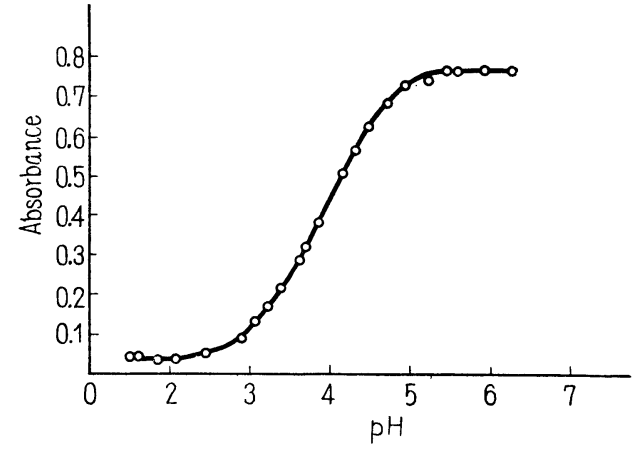

Fig. 6 Absorbance-pH diagram at $594 \mathrm{~m} / \ell$

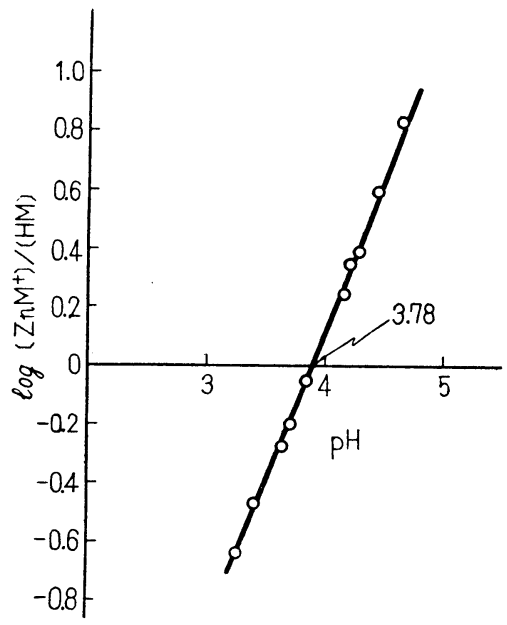

Fig. $7 \mathrm{pH}-\log \left\{\left[\mathrm{ZnM}^{+}\right] /[\mathrm{HM}]\right\}$ plot for determining of $p K^{\prime}$ of $z$ inc-chelate

もし,キレート化合物が $1: 1$ の組成を有するものであ れば，この直線の傾斜は 1 となるはずで実験值と一致し ている. 交点の $\mathrm{pH}$ ではキレート化合物生成に使用され る亜鉛量は少ないので, 亜鉛濃度は不变と見てよい. 従 って $p K_{2}=7.98$ によりキレート生成定数 $\log K$ は 5.90 と算出される.

$$
3 \text { 応用 }
$$

\section{$3 \cdot 1$ 吸光光度定量}

今までの実験より 0 〜 10 rの业釭を定量する方法を考 案した.ほとえど中性の検液に緩衝溶液 $10 \mathrm{~m} l$ を加えて $\mathrm{pH} 9.0$ とし, 試薬 $2 \mathrm{ml}$ で発色, $10 \mathrm{ml}$ のイソアミル アルコールで約 2 分間振温し抽出をおこない, 静置して 上層を綿フィルターを通して水分を除いてセルに移す。 $612 \mathrm{~m} \mu$ における吸光度を測定し, 空試験值を差引いて, あらかじめ作製された検量線により亜鉛量を決定する. 
一例として $6.54 \gamma$ の亜鉛を定量した結果を Table 1 に示した.

Table 1 Determination of zinc

\begin{tabular}{ccc}
\hline No. & Zn taken $(\gamma)$ & Zn found $(\gamma)$ \\
\hline 1 & 6.54 & 6.48 \\
2 & $"$ & 6.38 \\
3 & $\prime \prime$ & 6.48 \\
4 & $"$ & 6.46 \\
5 & $\prime \prime$ & 6.79 \\
6 & $" \prime$ & 6.50 \\
\hline
\end{tabular}

\section{$3 \cdot 2$ 金属指示薬}

高い $\mathrm{pH}$ においても, 亜鉛濃度が高いと水溶性の $1: 1$ のキレート化合物が生成しており，比較的安定である. しかし，時間がたつと次第に $1: 2$ のキレート化合物が 生成し始めて青色は褪色し, 沈澱が生成し始める.

亜鉛を EDTA で滴定する際，この試薬を指示薬とし て加光れば，亜鉛は 1:1 のキレート化合物を生成して いると考えてよい。

亜鉛と EDTA のキレート生成定数は 16.50 , 亜鉛と 試薬とのキレート生成定数は 5.90 であり, 適当な $\mathrm{pH}$ を選定すればキレート滴定の際の、金属指示薬として使用 できる。

$10^{-3} M$ の亜鉛を EDTA で滴定する際, 試薬の変色の 様子を上記のキレート生成定数を用いて, 種々の $\mathrm{pH} に$ おいて求めた・ただし, EDTA 添加による溶液の稀釈は なく，また補助キレート試薬は加えないるのとする3)。

Fig. 8 にこの結果を示す.

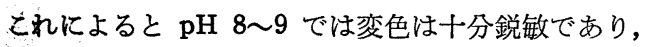
色墉の変化情青色から赤紫色である.この変色は逆滴定 を稀とっだ方が終点の判定は容易である．また指示薬 のキレート生成定数は比較的低いので, アンモニアなど の補助キレート試薬を多量に用いることは, 終点の判定 を困難にするので逆滴定をおこなった方がよい。

試料に過剩の EDTA を加え, 試薬を少量加え酸性で 橙黄色を呈しているならば, 稀アンモニア水を加えて赤 紫色の現われ始めるまで中和し, 綑衝溶液を加えて $\mathrm{pH}$ 9.0 とし，青色が現われ始めるまで亜鉛で滴定する.

Table 2 に $10 \mathrm{mg}$ の亜鉛を定量した結果を示した.

Table 2 Titration of zinc

\begin{tabular}{ccc}
\hline No. & Zn taken (mg) & Zn found (mg) \\
\hline 1 & 10.0 & $10.0_{5}$ \\
2 & $\prime \prime$ & $10.0_{4}$ \\
3 & $"$ & $10.0_{6}$ \\
4 & $" 1$ & $10.0_{2}$ \\
5 & $" 1$ & $10.0_{6}$ \\
6 & $" 1$ & $10.0_{5}$ \\
\hline
\end{tabular}

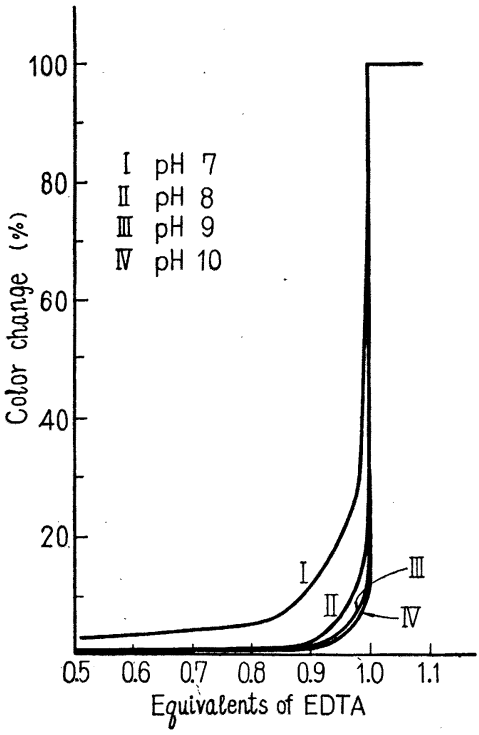

Fig. 8 Indicator color change for titration of zinc

\section{交献}

1) E. B. Sandell : "Colorimetric Determination of Traces of Metals", 2nd Ed., p. 47(1950).

2) G. P. Hilderbrand, C. N. Reilley : Anal. Chem., 29, 258 (1957).

3）上野景平：“キレート滴定法”, p. 79 (1956), (南江堂).

$$
\text { is }
$$

Determination of zinc with 2-(2-hydroxy-5methoxypheny lazo) -4-methylthiazole. [Studies on 2- (2-hydroxy -5- methoxyphenylazo) - 4- methylthiazole as analytical reagent. III.] Tadasi YANAGIHARA, Nobuhisa Matano, and Akira KAWASE (National Research Institute for Metals)

2-(2-Hydroxy-5-methoxyphenylazo) -4-methylthiazole gave two kinds of blue chelate compounds with zinc ion.

The one was formed when the concentration of zinc was high or when $\mathrm{pH}$ of the solution was low and this was soluble in water. The other was formed at higher $\mathrm{pH}$ and it was slightly soluble in water, but soluble in organic solvent such as iso-amyl alcohol.

By use of a continuous variation method (Fig. 3 ) and a slope ratio method (Fig. 4), the chelate compound slighthy soluble in water was composed of one atom of zinc and tow molecules of the reagent. The water solube chelate compound was found to be composed of one atom of zinc and one molecule of the reagent from studies of the relation between $\mathrm{pH}$ and light absorbancy.

For spectro-photometric determination of the 1:2 chelate compound in water at $\mathrm{pH} 9.0$, it was extracted with iso-amyl alcohol and the light 
absorbancy was measured at $612 \mathrm{~m} \mu$. The sensitivity was found to be $0.0019 \gamma \mathrm{Zn} / \mathrm{cm}^{2}$.

The formation constant was about 5.9 for water soluble chelate compounds. It can be used as a metal indicator and good result was obtained in the complexometric titration of zinc at $\mathrm{pH} 9.0$ with EDTA.

(Received June 20, 1958)

\title{
2-(2-ヒドロキシ-5-メトキシフェニルアゾ)-4-メチルチアゾール によるニッケルおよびコバルトの定量 ${ }^{*}$
}

\author{
柳 原 正, 俣野 宣久, 川瀬 晃 ${ }^{* *}$
}

2-(2-ヒドロキシ-5-メトキシフエニルアゾ)-4-メチルチアゾールはニッケルおよびコバルトと $\mathrm{pH}$ 7〜9 で青色のキレート化合物を生成し，水に難溶で沈澱となる．とれらはイソアミルアルコールなど の有機溶媒に可溶で水首からの抽出は容易に扣てなわれる.

連続変化法，傾斜比法により組成を決定し，金属 1 原子に対し 2 分子の試薬が結合しているてとがわ かった.とれらのイソアミルアルコール溶液はおの打の $620 \mathrm{~m} \mu, 607 \mathrm{~m} \mu$ に光度定量に都合のよい極 大吸収がある。乙の波長では試薬による吸収は少なく，微量のニッケルおよびコバルトの定量がおてな える。その感度は打のおの $0.0014 \gamma \mathrm{Ni} / \mathrm{cm}^{2}, 0.0018 \gamma \mathrm{Co} / \mathrm{cm}^{2}$ である。

\section{1 試薬および装置}

ニッケル標準溶液 : $5 \times 10^{-2} M$, 金属ニッケル $2.935 \mathrm{~g}$ を過塩素酸 $20 \mathrm{~m} l$ に溶解し水で $1 l$ に稀める.

コバルト標準溶液 : $10^{-2} M$, 金属コバルト $0.5894 \mathrm{~g}$ を 硝酸 $(1+3) 10 \mathrm{~m} l$ に溶解, 水で $1 l$ に稀める.

緩衝溶液 : 和光純薬製特級第二燐酸ナトリウム $23 \mathrm{~g}$ を水に溶解し $1 l$ とし，塩酸で $\mathrm{pH}$ を調節する。

試薬溶液 : $5 \times 10^{-4} M$, 合成試薬*** $124.6 \mathrm{mg}$ を和光 純薬特級メチルアルコールに溶解し $1 l$ とする.

そのほか, 薬品はすべて和光純薬製特級試薬を使用し た.

吸光度の測定にはベックマン DK 2 型自記分光光電光 度計を用い, $10 \mathrm{~mm}$ の石英製セルでおこなった。

$\mathrm{pH}$ の測定は柳本製作所製硝子電極 $\mathrm{pH}$ メーター 41 A型を使用した。

\section{2 ニッケルおよびコバルトキレート化合物}

\section{$2 \cdot 1$ 吸収曲線}

ニッケル：試薬 $1 \mathrm{ml}$ を緩衝溶液 $(\mathrm{pH} \mathrm{7.0)} 20 \mathrm{ml}$ に 加え, ニッケル標準溶液 $2 \mathrm{ml}$ を混合し, 生成したキレ 一ト化合物を $10 \mathrm{ml}$ のイソアミルアルコールで抽出す る. 抽出液は綿フィルターを通して水分を除き，イソア ミルアルコールを対照液として吸光度を測定した。

コバルト：試薬 $1 \mathrm{~m} l$ を緩衝溶液 $(\mathrm{pH} \mathrm{8.0)} 20 \mathrm{ml}$ に

*分析試薬としての 2-(2-ヒドロキシー5-メトキシフ エニルアゾ)-4-メチルチアゾールの研究（第 4 報）

** 科学技術庁金属材料技術研究所 : 東京都目黒区中目 黒

**** 第 1 報参照
加え, コバルト標準溶液 $2 \mathrm{ml}$ を混合し，ニッケルの場 合と同じように操作し，吸収スペクトルを測定した。

試薬：試薬 $1 \mathrm{ml} l$ 緩衝溶液 ( $\mathrm{pH} \mathrm{6.0)} 20 \mathrm{ml}$ に加え, 不純物として含まれる重金属を檃蔽するために EDTA を加えて $10 \mathrm{ml}$ のイソアミルアルコールで抽出，同様に して吸収スペクトルを測定した。これらの結果を Fig. 1 に示した.

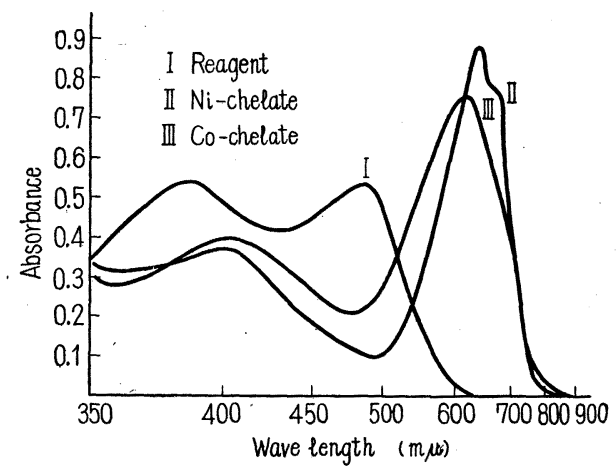

Fig. 1 Absorption spectra of reagent, nickel and cobalt chelate in iso-amyl alcohol

ニッケルおよびコバルトはおのおの $395,620 \mathrm{~m} \mu$ お よび 404,607 $\mathrm{m} \mu$ に二つの極大吸収を有し, 試薬自身は $382,485 \mathrm{~m} \mu$ に二つの極大吸収があるので $620,607 \mathrm{~m} \mu$ を用いてニッケルおよびコバルトの定量をおこなえば， 試薬自身による吸収も小さく，かつ感度も高いのでこの 波長で定量することにした.なお，キレート化合物のイ ソアミルアルコール溶液は安定で, 少なくとも 1 日は吸 収スペクトルおよび吸光度の変化は認められなかった。

吸収スペクトルの $620 \mathrm{~m} \mu$ および $607 \mathrm{~m} \mu$ でのそれ 